\title{
An Overview of Publicly Available Quantitative Cross-National Crime Data
}

\section{Introduction}

Although the media regularly reports on crime and violence worldwide, there is not a large body of academic research systematically analyzing cross-national crime patterns and trends or developing rigorous explanations of international variations in crime occurrences. Because of quantitative data limitations, the little knowledge that we have on the subject of cross-national crime variation tends to focus primarily on developed countries and often uses dated information (Stamatel, 2006).

However, there has been a renewed interest in comparative criminology over the past decade due to globalization and technological advancements that have improved the ability to conduct cross-national crime research (Howard, et al., 2000). In particular, there has generally been an increase in the amount and the quality of quantitative cross-national crime data available to researchers. This paper reviews the content, data collection methods, geographic and temporal coverage, and accessibility of three main sources of publicly available, quantitative cross-national crime data, with a particular emphasis on recent changes with respect to data availability. These sources are the International Police Organization (Interpol), the United Nations Crime Surveys, and the European Sourcebook ${ }^{2}$. There are also a number of reliability and validity issues to consider when analyzing quantitative cross-national crime data, but these issues are beyond the scope of this paper, and they have been discussed elsewhere in the academic literature (see for example, Neapolitan 1997; Howard et al., 2000; Howard and Smith 2003; Rubin 2006).

\section{Interpol}

Interpol data collected by the International Police Organization (http://www.interpol.int/) are the oldest quantitative cross-national data source. They have been collected annually from Interpol member nations since 1950. Police representatives are requested to complete a multilingual, one-page tabular form recording aggregate counts of offenses known to the police for the entire country for 14 offenses: murder, sex offenses, rape, serious assault, all kinds of theft, aggravated theft, robbery, breaking and entering, motor vehicle theft, other thefts, fraud, counterfeiting, drug offenses, and the total number of recorded crimes. Additionally, the police are asked to identify the percentage of these offenses that were attempts and the percentage of cases solved. Lastly, respondents are asked to provide information on the total number of offenders, and the percentage of whom are female, minors, and aliens.

The data collection process is voluntary. Representatives are given a set of definitions for each of the offense categories and requested to report the numbers for their countries according to these guidelines. It is important to note that Interpol does not provide any quality control measures on this data collection process. Accordingly, the organization provides a disclaimer in their publications stating that "the information given is in no way intended for use as a basis for comparisons between different countries" and that "the figures must be interpreted with caution" (Interpol 1999). However, given the limited number of quantitative cross-national crime data sources, researchers, the media, and others have regularly used Interpol data for cross-national comparisons. Interpol became concerned about the potential misuse of these data and stopped making them publicly available as of 2000 , to the dismay of many comparative researchers ${ }^{3}$ According to the Interpol web site, the crime statistics are currently only available to "authorized police users" (http://www. interpol.int/public/Statistics/ICS/downloadList.asp).

The first published Interpol statistics contained data from 36 nations in 1954, and the number has increased since then. In 1998, 116 countries reported data to Interpol, and 93 did so in 1999. However, the composition of countries varies from one year to the next. For example, only 82 countries reported data to Interpol in both 1998 and 1999. This represents approximately one-third of all countries in the world. According to Neapolitan (1997), 150 countries have reported data at least once to Interpol. Figure 1 illustrates which countries reported to Interpol in 1998 and 1999. The large and populous countries of China, India, and the United States are noticeably absent from the collection during this time, and coverage for the Middle East and Africa is uneven.

Interpol data are officially available only in hard copy. Until 1992 the reports, called International Crime Statistics, were published biennially, and then annually from 1993 until 1999 when they stopped releasing the data publicly. 


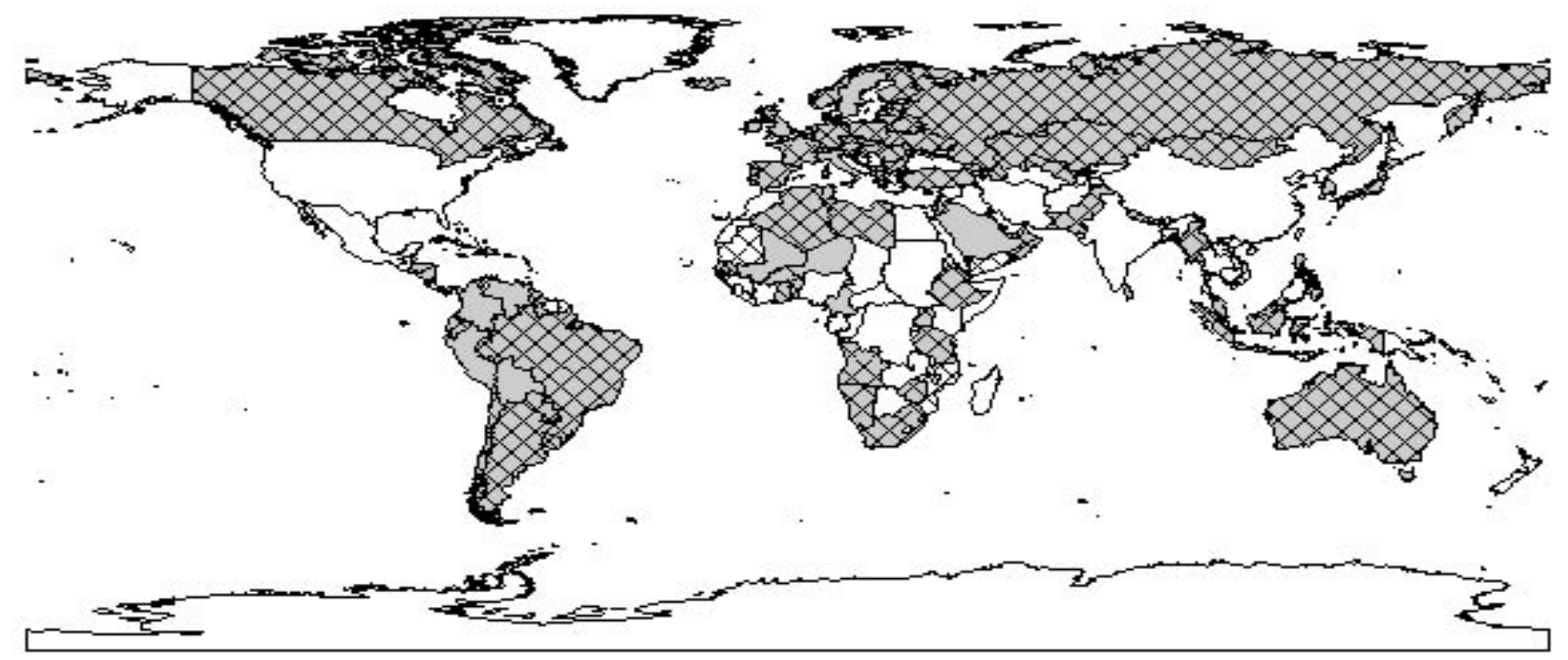

Figure 1 Countries Reporting Data to Interpol in 1998 and $1999 *$

* Grey shading indicates that the country reported data in 1998. Hatchmarks indicate reporting in 1999. White represents no reporting in either year.

It is not clear at this time whether Interpol will allow researchers to petition for access to their data. Some of the Interpol data are also available electronically in the Correlates of Crime: A Study of 52 Nations, 1960-1984 dataset (ICPSR 9258) compiled by Richard Bennett (1990), who is currently updating the collection ${ }^{4}$

\section{United Nations Crime Surveys}

The United Nations Crime Surveys (UNCS) (http://www. unodc.org/unodc/en/crime_cicp_surveys.html), officially called the United Nations Surveys of Crime and Operations of Criminal Justice Systems, have been collecting quantitative cross-national crime data from United Nations member states since 1970. The stated goal of this program is

"to collect data on the incidence of reported crime and the operations of criminal justice systems with a view to improving the analysis and dissemination of that information globally. The survey results will provide an overview of trends and inter-relationships between various parts of the criminal justice system to promote informed decision-making in administration, nationally and internationally" (United Nations Office on Drugs and Crime, 2007).

The UNCS sends multi-lingual questionnaires to coordinating officers in United Nations member countries. The coordinating officers are typically United Nations correspondents who compile the data with assistance from government employees from a variety of relevant departments, such as police and corrections. The questionnaires are designed to record aggregate, national-level figures about crime and criminal justice systems in four areas: police, prosecution, courts, and corrections. The police section includes the number of offenses reported to the police annually for 18 offenses: intentional committed homicide, intentional attempted homicide, intentional homicide committed with a firearm, non-intentional homicide, major assault, total assault, rape, robbery, major theft, total theft, automobile theft, burglary, fraud, embezzlement, drug-related crime, bribery and/or corruption, kidnapping, and total recorded crimes. Other data collected include personnel figures and budgets for different components of the criminal justice system, as well as the number of suspects by age and sex who encounter different stages of the criminal justice system. The United Nations provides a modest level of quality control on the collected data. The data are considered official statements by national governments about the extent of crime and the operations of criminal justice systems in their countries and, therefore, these data are considered more valid than the Interpol data.

The UNCS collects data in multi-year waves (see Table 1). The first five waves were administered every five or six years, then subsequent waves were issued every three years, and most recently, every two years. In response to the demand for more recent cross-national crime data, the UNCS has increased the frequency of administration and dissemination. Geographic coverage has varied by wave, but on average about 80 countries participated in 
any given wave. Countries' participation varies by wave, similar to Interpol, thereby making it difficult to construct longitudinal data series for a large number of countries. Figure 2 illustrates the geographic coverage of the UNCS for wave 7, covering 1998 to 2000. While coverage for North America and Europe is quite good, it is sparse or inconsistent for other regions of the world.

\begin{tabular}{|l|l|l|}
\hline Wave & Years & \# of Countries \\
\hline 1 & $1970-1975$ & 64 \\
\hline 2 & $1975-1980$ & 80 \\
\hline 3 & $1980-1985$ & 78 \\
\hline 4 & $1985-1990$ & 100 \\
\hline 5 & $1990-1994$ & 92 \\
\hline 6 & $1995-1997$ & 75 \\
\hline 7 & $1998-2000$ & 92 \\
\hline 8 & $2001-2002$ & 65 \\
\hline 9 & $2003-2004$ & 71 \\
\hline $\begin{array}{l}\text { Table 1 Geographic and Temporal Coverage in the } \\
\text { UNCS }\end{array}$
\end{tabular}

\begin{tabular}{|l|l|l|l|}
\hline & Interpol & UNCS & $\begin{array}{l}\text { European } \\
\text { Sourcebook }\end{array}$ \\
\hline Hardcopy & $1950-1999$ & & Waves1-3 \\
\hline ASCII & & $\begin{array}{l}\text { Waves 1-2, } \\
4-6\end{array}$ & \\
\hline Lotus 123 & & Waves 2-3 & \\
\hline MSExcel & & Wave 6-8 & Wave 1 \\
\hline SPSS & & Waves 2-6 & \\
\hline PDF & & Waves 6-9 & Waves 1-3 \\
\hline MSWord & & & Waves1-3 \\
\hline \multicolumn{2}{|l|}{} \\
Table 2 Quantive
\end{tabular}

Table 2 Quantitative Cross-National Crime Data Availability

albany.edu/sourcebook/) produced by the United States Bureau of Justice Statistics. This data collection effort began in 1990 in response to the growing demand for accurate and timely crime data, particularly in the context of the growing Council of Europe, and the concern over the limitations of the other two quantitative cross-national crime data sources. The content of the data collected by the European Sourcebook is similar to that of the other sources. In particular, the European Sourcebook includes
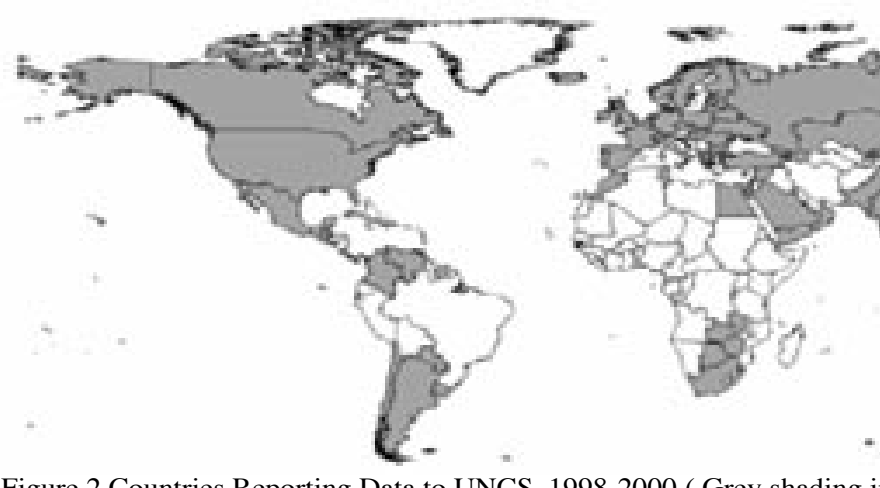
annual information on total number offenses reported to the police in each country for 14 types of crimes: total intentional homicide, completed intentional homicide, assault, rape, total robbery, armed robbery, total theft, theft of motor vehicle, bicycle theft, total burglary, domestic burglary, total drug offenses, total drug trafficking, and serious drug trafficking. Additionally, homicide victimization Figure 2 Countries Reporting Data to UNCS, 1998-2000 ( Grey shading indicates that the country reported data in the 1998-2000 wave)

data from the World Health Organization and select measures from the International Crime

The UNCS datasets are available electronically through the website of the United Nations Office on Drugs and Crime, although the file format available depends upon the wave of data collection (see Table 2). The first five waves are also available through ICPSR, including a harmonized longitudinal file for 1970 to 1994, which can be downloaded or analyzed online (Burnham and Burnham 1999).

\section{European Sourcebook}

The third, and newest, source of quantitative crossnational crime data is the European Sourcebook of Crime and Criminal Justice Statistics (http://www. europeansourcebook.org/), which was modeled after the Sourcebook of Criminal Justice Statistics (http://www.
Victimization Surveys are provided as points of comparison against the official records data reported by the police.

Like the UNCS, the European Sourcebook also collects information about the number of offenders by crime type, the percentage of offenders who are female, minors, and aliens, as well as information about caseloads, staffing, and dispositions related to prosecution, conviction, and corrections. However, the data about the criminal justice system are considered secondary indicators and are generally collected every five years, rather than annually.

Although the data for the European Sourcebook come from official records like the other two sources, the 
European Sourcebook differs in the way the data are collected and the high level of quality control imposed on the data collection effort. Each country participating in the effort has a national correspondent who is an expert in crime and criminal justice statistics and who is responsible for collecting and checking the data. These experts are typically either Ministry of Justice employees or academics. In addition to using standard classifications schemes for collecting data across countries, the national correspondents also agree upon certain quality control measures to ensure the accuracy and reliability of the data. Documentation for this collection is also more detailed than for Interpol and the UNCS data sources. For example, the European Sourcebook not only provides descriptions of crime definitions, but also detailed explanations of why some countries do not conform to these definitions. The European Sourcebook also provides a thorough discussion of the methodological limitations of this data collection.

The European Sourcebook began collecting data in 1990 and, like the UNCS, it is administered in waves. The first wave collected data from 1990 to 1996 and included 36 European countries. The second wave gathered data from 1995 to 2000 from 40 European countries. The third waved covered the years 2000 to 2003 for 37 countries, but it was a limited edition and not all of the tables were updated. In general the coverage for Europe is thorough and consistent, although some countries do not report data to this source, such as Serbia, Montenegro, and BosniaHerzegovina. Data from the European Sourcebook are available electronically from the Internet (http://www. europeansourcebook.org/) in a variety of file formats (see Table 2).

\section{Summary}

The three main sources of quantitative cross-national crime data share the same goal to provide reliable, annual counts of the frequency of occurrence of conventional crimes across countries and, for the UNCS and the European Sourcebook, measures of the operations of criminal justice systems worldwide. Although the crime count data for all of these sources come from police reports, the sources differ in terms of the way the data are collected and the amount of quality control exercised. Additionally, since reporting crime data to these international sources is voluntary and depends upon membership to the broader organization, the sources vary greatly in terms of geographic and temporal coverage. It may be tempting to simply combine data from these sources to maximize sample sizes, but researchers have noted considerable inconsistencies across the sources, particularly for certain offenses and time periods (e.g., Bennett and Lynch, 1990; Howard and Smith, 2003; Gottschalk, et al., 2007). Quantitative cross-national crime data collections have improved recently with respect to the frequency of collection, greater electronic availability, and to some extent, improved quality control. Nonetheless, there are still numerous methodological concerns regarding these data and researchers should use them carefully and responsibly.

\section{References}

Bennett, Richard, and James Lynch. 1990. "Does a Difference Make a Difference? Comparing Cross-National Crime Indicators." Criminology 38:153-181.

Bennett, Richard R. 1990. "Correlates of Crime: A Study of 52 Nations, 1960-1984 [Computer file]." Ann Arbor, MI: Inter-university Consortium for Political and Social Research (ICPSR 9258) [distributor].

Burnham, R.W., and Helen Burnham. 1999. "United Nations World Surveys on Crime Trends and Criminal Justice Systems, 1970-1994: Restructured Five-Wave Data [Computer file].” Ann Arbor, MI: Inter-university Consortium for Political and Social Research (ICPSR 2513)[distributor].

European Sourcebook of Crime and Criminal Justice Statistics. Retrieved July 3, 2007 from http://www. europeansourcebook.org/.

Gottschalk, Martin, Tony Smith, Gregory J. Howard, and Bradley R. Stevens. 2006. "Explaining Differences in Comparative Criminological Research: An Empirical Exhibition." International Journal of Comparative and Applied Criminal Justice 30:209-234.

Howard, Gregory J., Graeme Newman, and William Alex Pridemore. 2000. "Theory, Method, and Data in Comparative Criminology." Pp. 139-211 in Criminal Justice 2000, Volume 4: Measurement and Analysis of Crime and Justice. Washington, D.C.: U.S. Department of Justice: National Institute of Justice.

Howard, Gregory J., and Tony Smith. 2003. "Understanding Cross-National Variations of Crime Rates in Europe and North America." Pp. 23-70 in Crime and Criminal Justice In Europe and North America 1995-1997, edited by Kauko Aromaa, Seppo Leppa, Sami Nevala, and Natalia Ollus. Helsinki, Finland: European Institute for Crime Prevention and Control (HEUNI).

International Police Organization (Interpol). 1999. International Crime Statistics. Lyons: France: ICPOInterpol General Secretariat.

Neapolitan, Jerome. 1997. Cross-National Crime: A Research Review and Sourcebook. Westport, CT: Greenwood Press.

Rubin, Marilyn Marks. 2006. “Assessing the Reliability of UN and Interpol Crime Statistics: A John Jay College Analysis," paper presented at the annual meeting of the 
American Society of Criminology. Los Angeles, CA.

Stamatel, Janet P. 2006. "Incorporating Socio-Historical Context into Quantitative Cross-National Criminology."

International Journal of Comparative and Applied Criminal Justice 30:177-207.

United Nations Office on Drugs and Crime, "United

Nations Surveys on Crime Trends and the Operations of Criminal Justice Systems.” Retrieved July 3, 2007 from

http://www.unodc.org/unodc/en/crime_cicp_surveys.html.

\section{Endnotes:}

1. A previous version of this paper was presented at the IASSIST meeting in Ann Arbor, Michigan, 2006. Janet P. Stamatel is an Assistant Professor in the School of Criminal Justice and the Department of Informatics at the University at Albany, 135 Western Ave., Albany, NY 12209, jstamatel@albany.edu.

2. The three sources discussed in this paper are all official records data. Quantitative cross-national crime data are also collected from victimization surveys (see the International Crime Victims Surveys at http://www.unicri.it/wwd/ analysis/icvs/index.php) or self-report delinquency surveys (International Self-Report Delinquency Study). Although these are important sources of data, they have limited geographic and temporal coverage and, therefore, they are not used as often for cross-national crime analyses. Some researchers also use mortality data from the World Health Organization (http://www.who.int/whosis/en/) to analyze aggregate homicide victimizations. This is an important source of cross-national homicide data, although it is not as easily accessible as the sources discussed in this paper and it only provides a measure of one criminal offense.

3. Dr. Rosemary Barberet, John Jay College of Criminal Justice, will present a paper at the 2007 meeting of the American Society of Criminology titled "The Contribution of Interpol Crime Data to Cross-National Criminology" that will examine the impact of the loss of access to these data on comparative crime research.

4. Information obtained from personal communication with the author 